\title{
ANALYSIS OF A RESIDENTIAL BUILDING ENERGY CONSUMPTION AS "BASE MODEL" IN TRIPOLI, LEBANON
}

\author{
S. YATHREB \\ Faculty of Architectural Engineering, Beirut Arab University, Tripoli, Lebanon.
}

\begin{abstract}
The interest in energy performance of buildings in Lebanon has increased in the last few years. Indeed, many organizations are evaluating the commercial buildings' energy performance in order to increase the commercial sector energy efficiency. Since residential buildings occupy $47 \%$ of the overall end-use energy consumption in Lebanon, therefore; the development of a rating methodology for residential energy performance should also be significant. This study reveals the results of a field survey of residential apartment buildings in the city of Tripoli. The survey focuses on the newly built-up extended zones of the city (Basateen El-Mina and Basateen Trablous), that are subject to the current building code. Based on a questionnaire and a monitoring survey, a building performance simulation model was created to reflect the average energy consumption characteristics for the most residential building accumulation. This benchmark model describes the energy use report for heating, cooling, lighting, domestic hot water systems and appliances with respect to the building's layout, orientation and construction. The output data of the simulation will be compared with collected EDL (Electicite du Liban) bill. The aim of this study is to develop representative building energy data sets and benchmark models for the Lebanese residential sector specifically in the coastal zone area. Having a "base model "as a benchmark for existing residential buildings will form the basis of a research on specific building technologies and measurements of progress towards the Zero Energy Building goal.

Keywords: building performance simulation, energy consumption model, residential building.
\end{abstract}

\section{INTRODUCTION}

Lebanon depends on imported fossil fuels to run its power-generating utilities. The power production of utilities is insufficient to meet the growing demand of the market due to the fact that their capacities are less than needed, and their production processes are inefficient. In addition, the rapid development of urbanization, economic development, living standards and climate change, have increased the Lebanese building energy consumption dramatically. In 2030, the energy consumption of buildings in Lebanon is expected to be $250 \%$ of the energy consumption in 2010 [1]. The main contributor to this growth in energy demand is the inadequate performance of the existing buildings, such as the enormous demand for small air conditioning units, thermal comfort issues, and insufficient daylighting. Given that residential sector accounts $47 \%$ of the produced energy, any possible saving in the sector's consumption is a factor in the growth of the national economy, and an improvement in environmental conditions [2].

Treating the energy consumption of an existing residential building as a relatively independent statistical object is good for systematically accumulating the underlying data for new residential building design and understanding the basic conditions that affect building energy consumption. Therefore, we should establish a relative "benchmark" and find out effective methods for studying building energy consumption as soon as possible. The benchmark is meant to model the real existing buildings that meet the requirements of the current building law adopted in the Lebanese construction market. The benchmark building definitions are 
intended to act as targets to rate the energy performance of individual existing or proposed buildings.

Setting national building energy benchmarks would benefit stakeholders in many ways. In addition to energy consumption monitoring, it would assist the government in formulating measures to reduce the impact of buildings on the environment. The building owners, or tenants, will be aware of the energy performances of their buildings, and therefore they would take the necessary steps to improve energy efficiency of their buildings. Based on the benchmark models, a green building could be developed by consultants and designers using new ideas and best practice in designing or retrofitting. This benchmark will be used for research in assessment studies, optimization work, controls, daylighting, ventilation, indoor air quality, and other areas. In addition, it might be used in the development of energy codes for buildings and building appliance standards.

In contrast to rating performance based on actual measured data, there are many tools available that estimate expected energy performance of buildings based on engineering models, some with correction against actual measured usage, e.g. DOE-2, e-Quest, etc. Therefore, we rely to use Design-builder from Energy-Plus to validate the survey results.

\section{BACKGROUND}

The measured energy performance of existing buildings has been witnessed in the last few years of working on energy benchmarking in many countries. As Sharp stated in 1996, "Energy benchmarking offers initial building energy performance assessment without rigorous evaluation. 'Seeing' that building energy use is excessive is the first step to change."[3]. Different methods have been applied to develop the benchmark model in a different study. Commercial Buildings Energy Consumption Survey (CBECS) which is a national study in the United States, relied on a process commonly known as a step-wise linear regression, in order to identify the primary drivers of building energy consumption [4]. However, the Residential Energy Consumption Survey (RECS) in 1993 done by the US Dept. of Energy (DOE) had relied on collecting data through survey analysis on how households in this country use energy. The data cover household and housing unit characteristics, annual fuel consumption and expenditures by end use for five fuels, and estimates energy end uses such as space heating and cooling, lighting, water heating, and appliances [4]. The third method to estimate the energy consumption was the neural network method adopted by "Aydinlap et al." for the Canadian residential sector [5]. In this study, we rely on a survey study in order to develop our benchmark for Lebanese residential energy use.

In Lebanon, the first local energy audit firm got into business in 1996. However, in this period the firm business was weak due to a major barrier of funding. Since 2002, the Lebanese Centre for Energy Conservation (LCEC) initiated a nationwide program on energy audits for medium and large consuming facilities. By the end of 2008, LCEC has financed and supervised more than 100 audits [6]. Much of the energy performance survey work in Lebanon, is directed towards commercial buildings or large commercial enterprises. Because residential buildings account for over half of all buildings' energy use in Lebanon, an effort was started by the authors to assess the feasibility of developing an energy performance rating (benchmarking) tool for residences based on actual measured energy consumption.

\section{METHODOLOGY}

The methodology implemented in this study includes aspects which determine the energy consumption characteristics of typical residential buildings in Tripoli city. The first step was 
to identify typical residential building typology and characteristics through a literature review based on past official statics. The second step was to identify the typical energy consumption profile through field survey. The survey plan included a description of a comprehensive set of building construction, equipment and dimensions. For collecting relevant data, in addition of the in-situ measurements by using data loggers and sensors, a specific questionnaire was prepared. Based on personal interviews in 41 household apartments, the questionnaire consisted of the nine topical sections with the total of 63 questions. The questionnaire's aim is to obtain data on the following aspects of the households' energy consumption:

- Building characteristics.

- Apartment occupancy rates.

- Availability of electrical appliances in households.

- Lighting efficiency and their operation.

- Domestic hot water.

- Space heating.

- Air-conditioning.

- Energy consumption (by type of fuels and energy).

- Behavioral practice in households towards efficient use of energy.

For the third step, actions were taken to develop a representative benchmark model of typical apartments and conduct parametric simulations by using Energy Plus program. Hourly weather readings for the year 2005 was extracted from Meteonorm 7.1.3 software to be used in the simulation process.

\section{CASE STUDY SELECTION}

Modeling all existing buildings is impractical, so we aim to select a small number of reference buildings that could reflect the reality in the residential building stock as precisely as possible. Climatically, Lebanon is composed of four climatic zones: Zone1-Costal, Zone2-Western Mid-Mountain, Zone3-Inland Plateau and Zone4- High Mountain [7]. In this research, our concern is the coastal zone climate that contains the highest proportion of urban growth. Tripoli ( $\left.34^{\circ} 26^{\prime} 0^{\prime \prime} \mathrm{N}, 35^{\circ} 51^{\prime} 0^{\prime \prime} \mathrm{E}\right)$, the largest city, in the North coastal region of Lebanon, was chosen as a case study, due to the limitation of research capability and the potential for easy data collection. The field study was conducted in the new extension zones of the city (Basateen El-Mina and Basateen Trablous zones), where the majority of the buildings' construction in these zones accommodate the initial requirements of the current building Law issued in 2005 (Fig. 1). Therefore, the assessment of energy consumption of these zones buildings, could be considered as an energy evaluation of the current and near future building stock that apply the current building law.

According to the Central Administration of Statics (CAS), the majority of the households in Lebanon (72.6\%) live in apartments in residential buildings and very few live in other types of dwellings such as villas or improvised dwellings [8]. For this reason, the study focuses on multifamily apartment buildings that represent the vast majority residential type in Tripoli. Another notable characteristic of dwelling in Lebanon is the relatively large number of living spaces (without kitchens and bathrooms). In fact, the majority of dwellings had at least four rooms while a very few were composed of only one room (3\%) [8]. Therefore, the survey plan was aimed at screening and selecting two middle class neighbourhoods where the majority of apartments has an area between $130-$ and $180 \mathrm{~m}^{2}$. The 


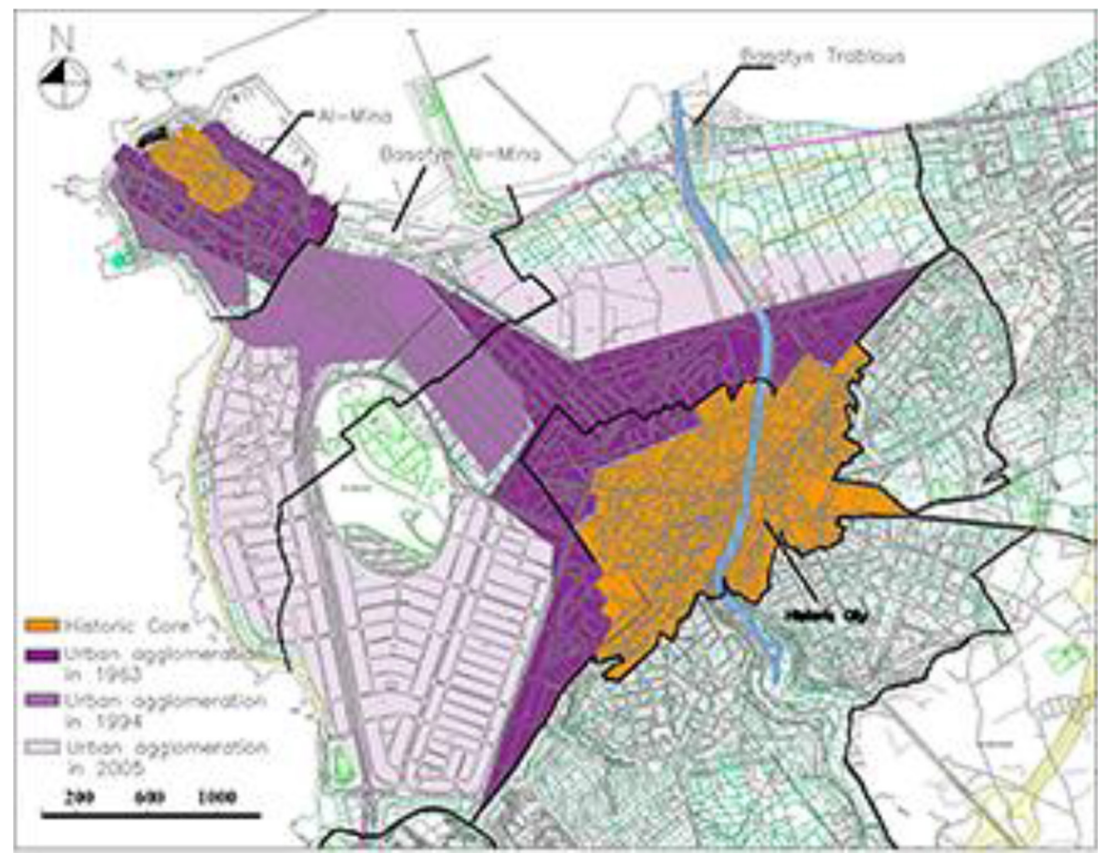

Figure 1: Urban agglomeration of Tripoli city during the time [9].

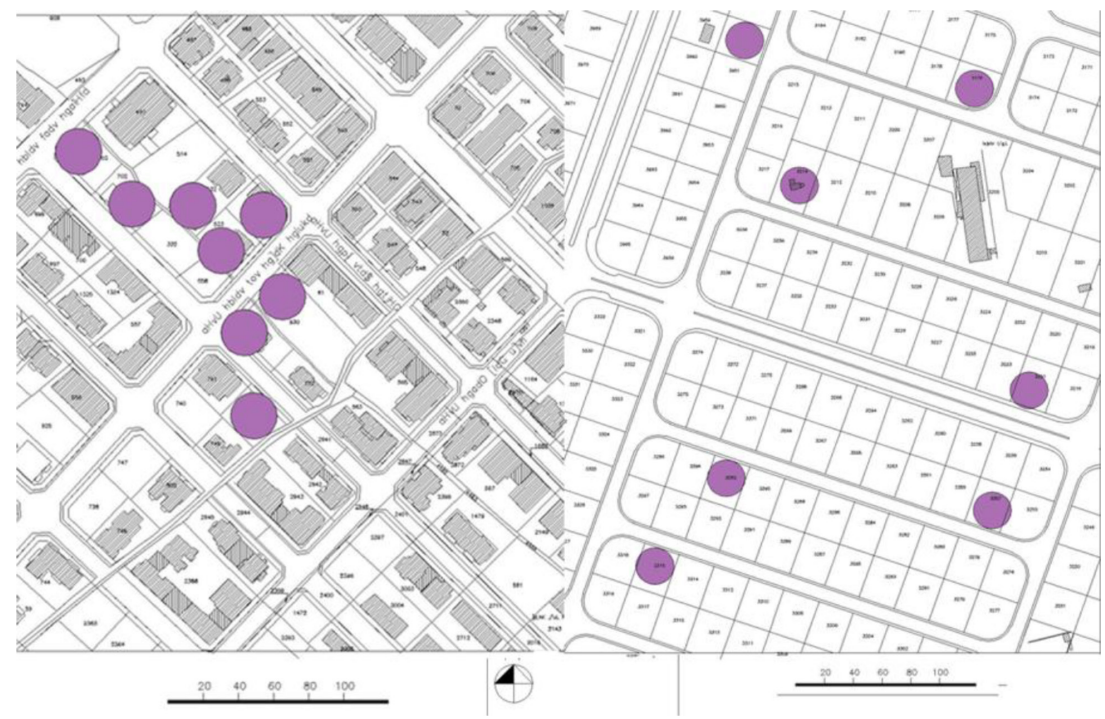

Figure 2: The selected neighbourhoods in "Basateen El-Mina" and "Basateen Trablous".

selection included two neighbourhoods, named Condor in "Basateen El-Mina" zone and "Dam \& Farez" in "Basateen Trablous" as shown in Fig. 2. The site observation shows that those residential neighbourhoods have buildings in modular lots. Reinforced concrete associated with concrete blocks represents the main components in the construction of these buildings. 


\subsection{Representative residential building characteristics}

As observed from the data collected, there are two typical common blocks identified in the case study zones; thus resulting in two typologies selected and defined as representative residential building blocks for this study. The building description is based on three main categories: Program, Form and fabric. Typology 1 which has a rectangular layout, that consists of two apartment units per floor. However, Typology 2 that consists of three apartment units per floor, has an L shape floor layout. The position of these typologies within the urban context and building adjacent was also taken into consideration (Figs 3 and 4). Typology 1 presents $79 \%$ and $70 \%$ from the building stock in the Basateen Trablous and Basateen El-Mina respectively. However, Typology 2 presents the minor percentage (21\% and 30\%) of the building stock in the two case zones.

Typology 1 is a block with a rectangular base that has $22 \mathrm{~m} \times 19.5 \mathrm{~m}$ as dimensions. It consists of two typical apartments per floor, where each apartment has $180 \mathrm{~m}^{2}$ as gross area. Typology 2 is a block with $\mathrm{L}$ shape base that has $14 \mathrm{~m} \times 12.5 \mathrm{~m} \times 12.5 \mathrm{~m} \times 11 \mathrm{~m} \times 25.5 \mathrm{~m} \times$
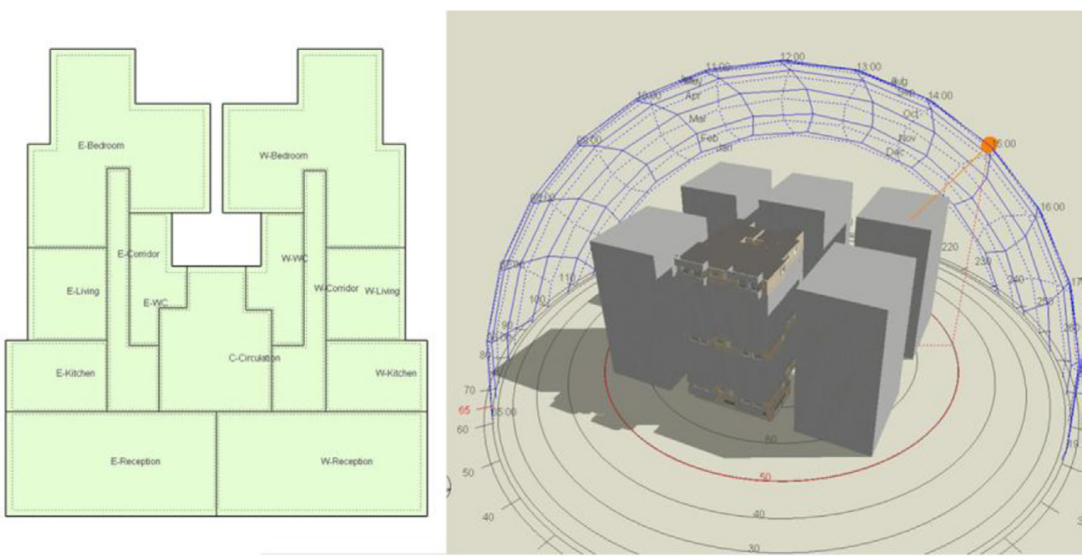

Figure 3: Typical plan of Typology 1 and its $3 \mathrm{~d}$ modelling in the urban context.
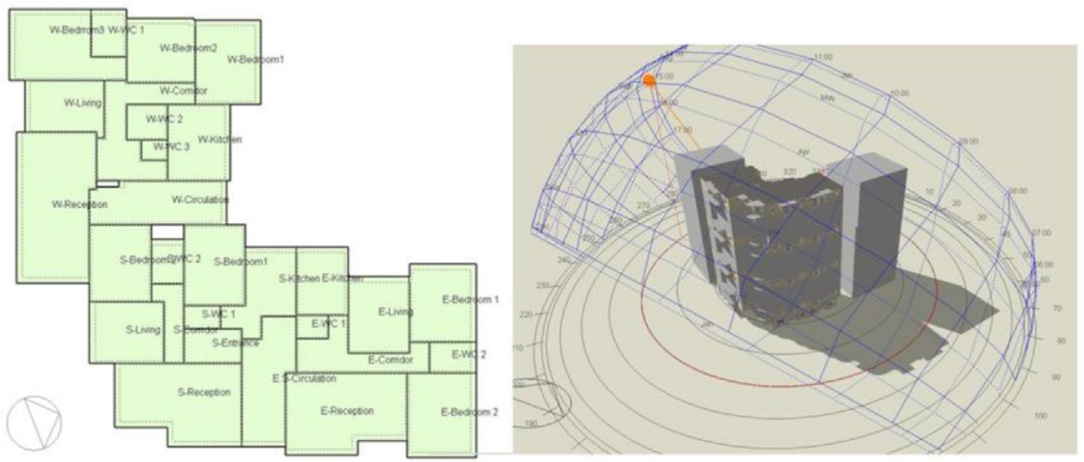

Figure 4: Typical plan of Typology 2 and its $3 \mathrm{~d}$ modelling in the urban context. 
$24.5 \mathrm{~m}$ as dimensions. It consists of three apartments per floor, one apartment with $160.5 \mathrm{~m}^{2}$ as gross area, and two apartments with $132 \mathrm{~m}^{2}$ as gross area for each one. The basic building construction in the two typologies is a reinforced concrete skeleton system with concrete hollow blocks for building envelope and interior partition. External openings are single clear glazing, and have $3 \mathrm{~mm}$ thickness with an aluminium frame. To address the different orientation of the surveyed apartments, the representative models were generated by simulating with their actual chosen orientation and after rotating the entire building 90, 180, and 270 degrees, we can average the results for different orientation in different locations. Table 1 summarizes the general geometrical variables and envelopes construction description of the benchmark models.

Table 1: Geometrical thermal and construction parameters of typology 1 and typology 2.

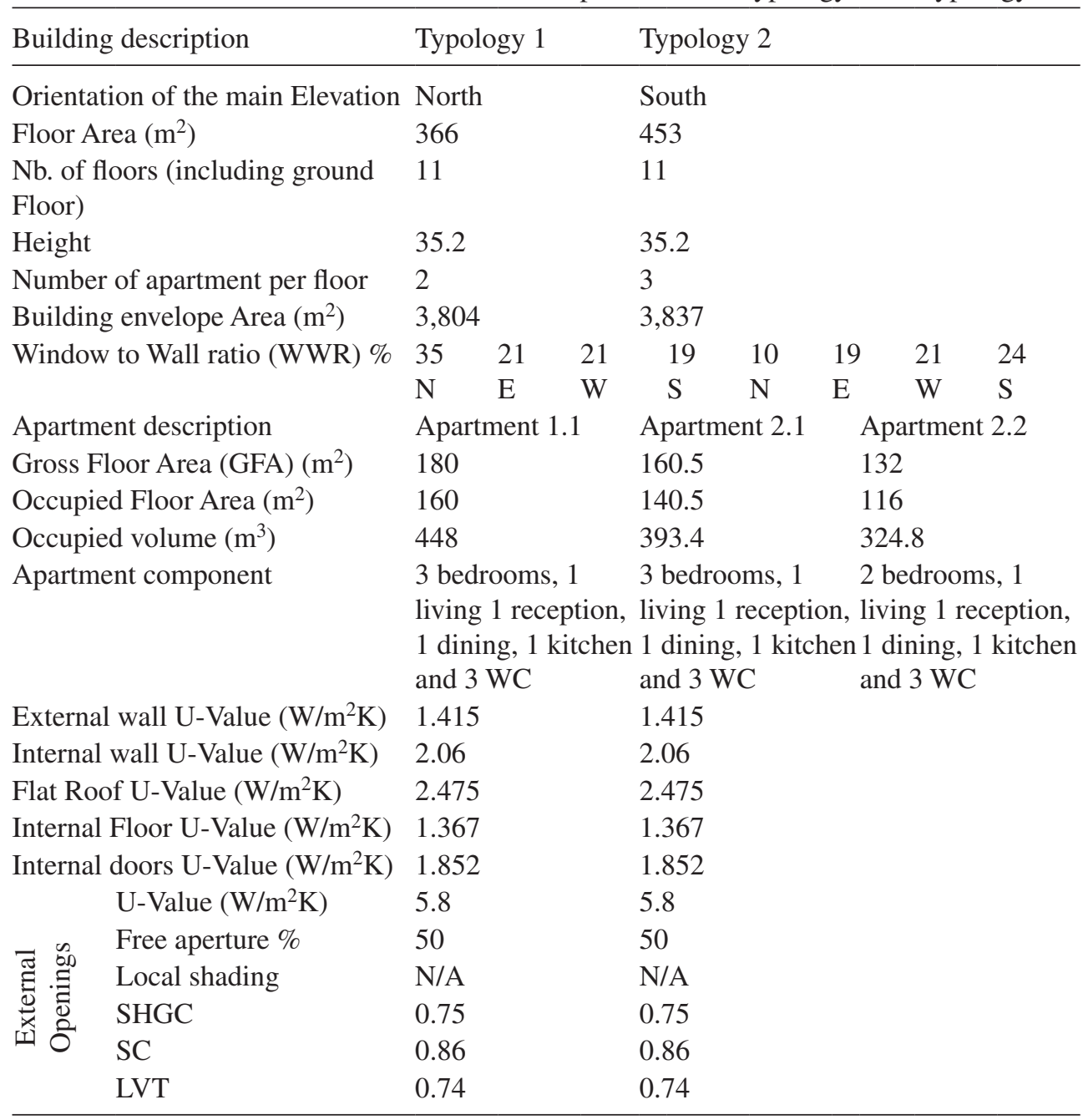




\section{RESIDENTIAL ENERGY MODEL PARAMETERS}

For each of the following issues, the results from the survey are presented and compared to macro data for Lebanon's wide range in order to estimate the energy profile that characterizes the majority of residential buildings in the Lebanese coastal cities. The final energy consumption is the sum of all end use consumptions of different household energy carriers. The necessary variables contained for each case study are collected based on six main categories: occupancy rate, plug load intensities, lighting, domestic hot water and heating and cooling intensities. Combining the collected data in a representative simulation model will be presented in the next section.

\subsection{Occupancy rates}

Occupancy has a great influence on internal loads and ventilation requirements in the apartment, thus residential energy consumption is affected by the variety of activities, such as walking through the rooms, entering or leaving the apartment. First, the average occupancy density in the case study area was scored $45.2 \mathrm{~m}^{2}$ for each person, which is considered a low density when compared to the 2005 Census, where the median area of dwelling in Lebanon was estimated at $30 \mathrm{~m}^{2}$ per person [8]. Referring to the survey questionnaire results, the characteristics of the family type in the case study zone are based on a nuclear family where the adult man who is the head of the household would be away from home during the daytime, while his wife stays at home in most cases or is a female worker like other family members that would be away from home during the morning period (8:00-15:00). To validate the occupancy schedules, a monitoring was done in 6 typical different apartments using the UX90-006M: HOBO UX90 Occupancy/Light Logger. The result of monitoring is summarized by the occupancy schedules illustrated in Fig. 5.
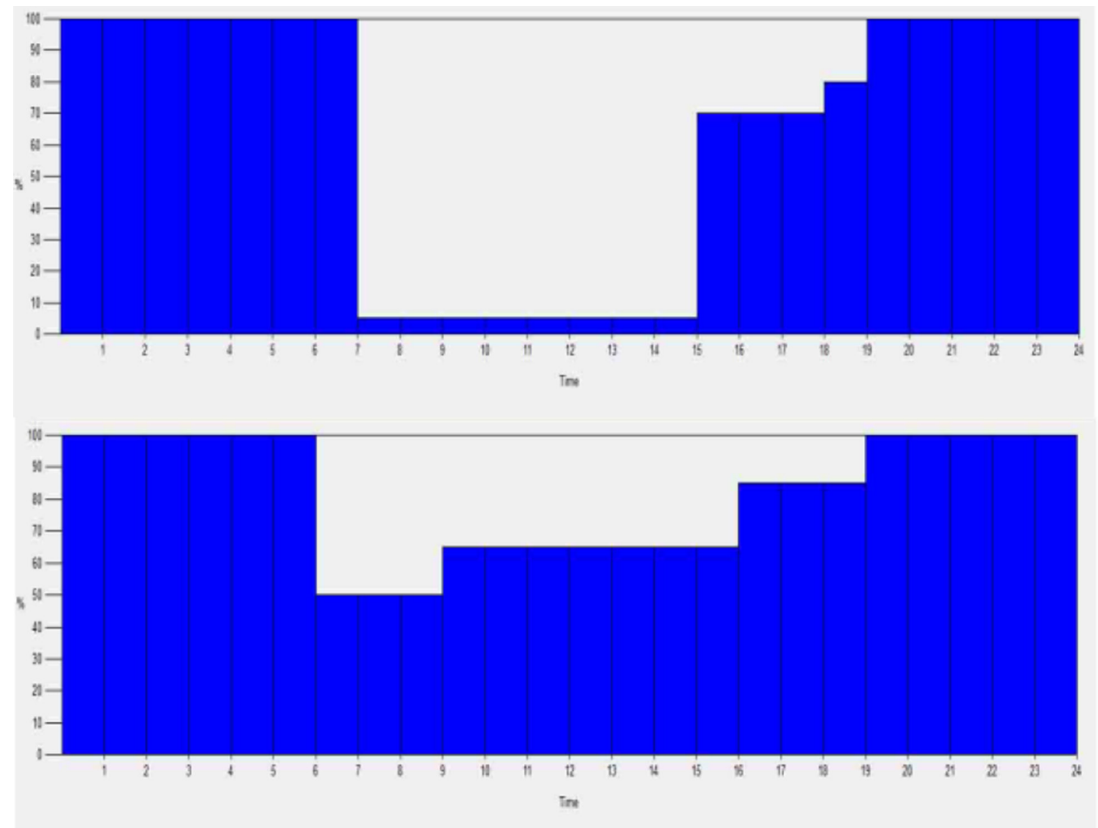

Figure 5: Occupancy schedules during typical winter workday (Top) and typical summer day (Bottom). 


\subsection{Plug load intensity and schedules}

A checklist of electrical appliances was done in order to estimate the plug load intensities and their operation schedules in the case study apartments. The survey focuses on commonly available appliances in the majority of the apartment's sample. Each electrical appliance seems to have a specific usage pattern and power load. Figure 6 summarizes the power in watts for each domestic electrical appliance. To facilitate and unify the communication of plug loads for the estimated model, all appliance power was summarized under one unit of power density. The average plug load peak power intensity is $52.8 \mathrm{~W} / \mathrm{m}^{2}$ and the watt hours used per day was scored $6688.3 \mathrm{Wh} /$ day in a typical occupant day.

\subsection{Lighting intensity and schedules}

The monitored data shows that the gap between lighting and occupancy in living spaces is $13 \%$ on a typical working day and $26 \%$ on the holidays. Therefore, we can conclude that the energy consumed by lighting is higher on holiday. On the other hand, the lighting power density installed in different spaces of the house depends on the type and number of the light bulbs that are installed. The dominant types of lamps used in the case study apartments were incandescent lamps and compact fluorescent lamps (CFL). Based on the survey checklist, the average lighting-power intensity for living room and bedrooms are 9 to $12.5 .5 \mathrm{~W} / \mathrm{m}^{2}$ as shown in Fig. 7. Those values were adopted as the typical lighting power intensities for the established models.

\subsection{Domestic hot water}

As found in the survey, $93 \%$ of respondents use electric heaters for water heating purposes, with only $7 \%$ using solar thermal technologies to heat domestic water. Water heating is mostly used for shower needs, clothes washing and dish washing. Taking into account all possible household usage and purposes of hot water, the need for hot water is

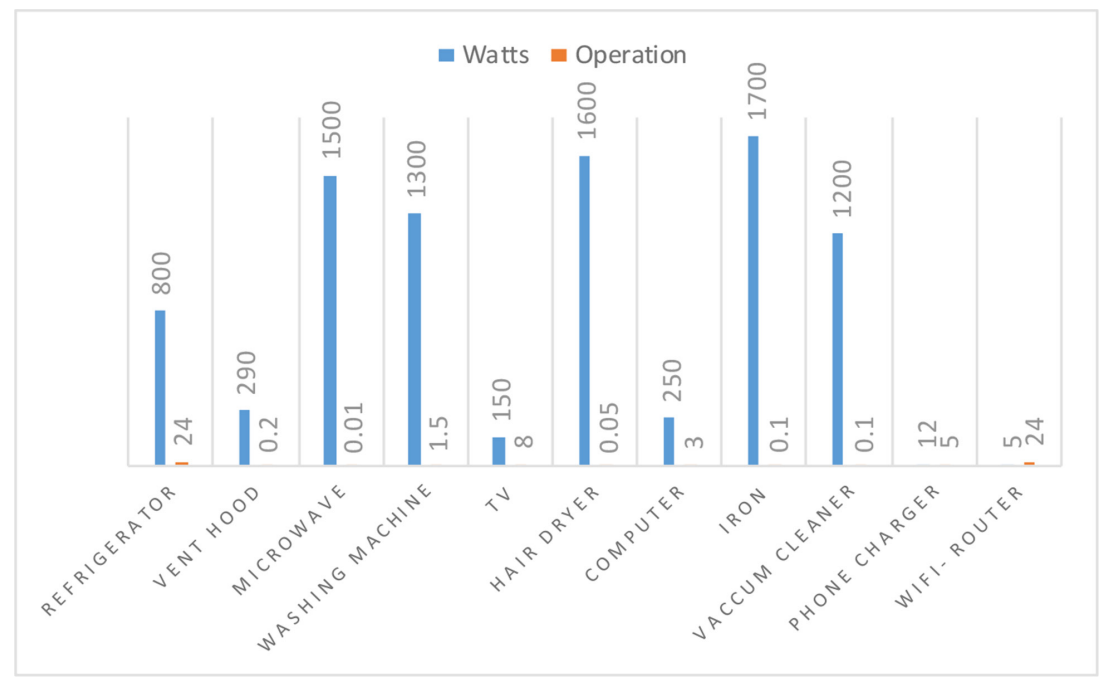

Figure 6: Household equipment intensity and operation. 


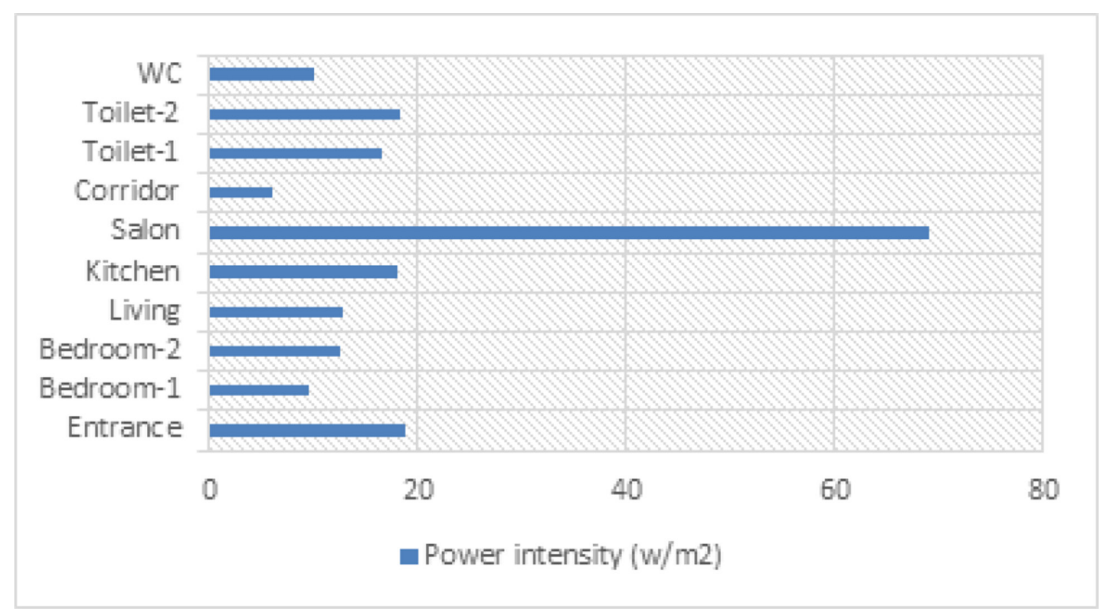

Figure 7: Lighting intensity in apartment rooms.

evenly split between the summer and winter time. During the summer, the average DHW use is estimated to be $5 \mathrm{~L} / \mathrm{m}^{2} /$ day, while in winter the hot water consumption increases to $21 \mathrm{~L} / \mathrm{m}^{2} /$ day.

\subsection{Heating load intensity}

According to the survey, most of the end-users prefer using electric heating units for space heating. Around $80 \%$ of the users use electric heating, while around $20 \%$ use gas heating units or others such as combustible wood. The heating system is operated in December, January and February, with $92 \%$ of the users operating their heating systems on January compared to $88 \%$ in February and $76 \%$ in December [15]. During winter days, users tend to operate their heating units on a daily basis, with $67 \%$ of the users doing so mainly during evenings and afternoons along with $76 \%$ and $43 \%$, respectively. The timing of operation is summarized in a usage schedule added in the simulation model.

\subsection{Cooling load intensity}

95\% of the surveyed apartments had at least three wall mounted Fan coil unit (Split unit), mainly in living, reception and master bedroom. Only $15 \%$ of the responds were content to use only fans in summer days. The survey results indicate that the use of fans was mainly during the spring season at noon (April, May) and during the low temperature period in the summer season. Therefore, the peak operation time for Air-conditioning, is in June, July and August which explains the high load on power in these months.

\section{6 "BASE MODEL" SIMULATION}

Based on the previous description of internal load and usage schedules, two simulation models were constructed by using Design Builder software. Table 2 summarizes the major simulation input parameter values, and the calculated output as total annual energy consumption in the two typologies. The validity of the estimation has been further checked against collected monthly EDL bill. 
Table 2: Base Model input data and the average expected annual energy use.

\begin{tabular}{|c|c|c|c|}
\hline \multicolumn{2}{|c|}{ Model Input Parameters } & \multirow{2}{*}{$\begin{array}{l}\text { Typology } 1 \\
0.025\end{array}$} & Typology 2 \\
\hline \multirow[t]{4}{*}{ Activity } & Occupancy density (people/m2) & & \\
\hline & Metabolic factor & \multicolumn{2}{|c|}{0.9} \\
\hline & Occupancy schedules & \multicolumn{2}{|c|}{ Previously mentioned } \\
\hline & Holiday (day/year) & \multicolumn{2}{|c|}{38} \\
\hline \multirow{13}{*}{$\begin{array}{l}\text { Plug Loads } \\
\text { Lighting }\end{array}$} & Power density (w/m2) & \multicolumn{2}{|l|}{52.8} \\
\hline & \multicolumn{3}{|l|}{ Luminaire Type: } \\
\hline & Suspended (SP) & $45 \%$ & $55 \%$ \\
\hline & Surface Mount (SM) & $10 \%$ & $16 \%$ \\
\hline & Recessed can (Rc) & $35 \%$ & $25 \%$ \\
\hline & Recessed cove fixture(Ro) & $7 \%$ & $10 \%$ \\
\hline & Wall sconce & $3 \%$ & $4 \%$ \\
\hline & \multicolumn{3}{|l|}{ Lighting Type: } \\
\hline & Incandescent(I) & $35 \%$ & $43 \%$ \\
\hline & Compact Fluorescent (CFL) & $52 \%$ & $45 \%$ \\
\hline & LED & $13 \%$ & $12 \%$ \\
\hline & IL luminance (lux) & 125 & 110 \\
\hline & Power intensity (w/m2) & 28.1 & 27.4 \\
\hline \multirow[t]{2}{*}{ DHW } & Heater Fuel & Electrical & Electrical \\
\hline & Consumption rate (1/m2-day) & 15 & 12 \\
\hline \multirow[t]{4}{*}{ Heating } & Type & \multirow{2}{*}{\multicolumn{2}{|c|}{$\begin{array}{c}\text { Electrical } \\
\text { Portable unit/Split AC }\end{array}$}} \\
\hline & & & \\
\hline & $\mathrm{CoP}$ & \multicolumn{2}{|c|}{2.81} \\
\hline & Heating Set Point & \multicolumn{2}{|c|}{18} \\
\hline \multirow[t]{4}{*}{ Cooling } & Type & \multicolumn{2}{|c|}{ Split AC/ Fans } \\
\hline & $\mathrm{CoP}$ & \multicolumn{2}{|c|}{9.57} \\
\hline & Airflow(CFM) & \multicolumn{2}{|r|}{233} \\
\hline & Cooling Set Point & \multicolumn{2}{|r|}{21} \\
\hline \multicolumn{2}{|c|}{ Total Energy Consumption Kwh/m2 } & 51.64 & 40.49 \\
\hline \multicolumn{2}{|c|}{ Total Energy Consumption from EDL ( Kwh/m2) } & 44.06 & 39.96 \\
\hline
\end{tabular}

By comparing the total energy needed in the simulation with the official bill, the simulated one was higher by $15 \%$ in Typology 1 and so close in Typology 2 (2\%). As shown in Fig. 8, the estimated monthly electricity consumption curve is proportional to the annual simulated data overall. Indeed, The EDL consumption curve is slightly down the limits than that of the predicted consumption by about $15 \%$ in Typology-1, during the cooling time (July and August), and 10\% during the rest of the year. However, the comparison in Typology-2 showed the EDL consumption curve exceeding the simulated data curve by an average of $5 \%$. We can conclude that the occupant attitude and behaviour is different in the two typologies. In fact, it was noticed that during the survey that many people leave their homes for a long period during the holidays in Typology-1 that certainly represents families with high income and different life styles when compared to typology-2. Another analysis to this deviation is that the climate data used in the simulation dates back in 2005 Tripoli Climate data even though the collected bill represents 2014 electricity consumption. As a conclusion, two 


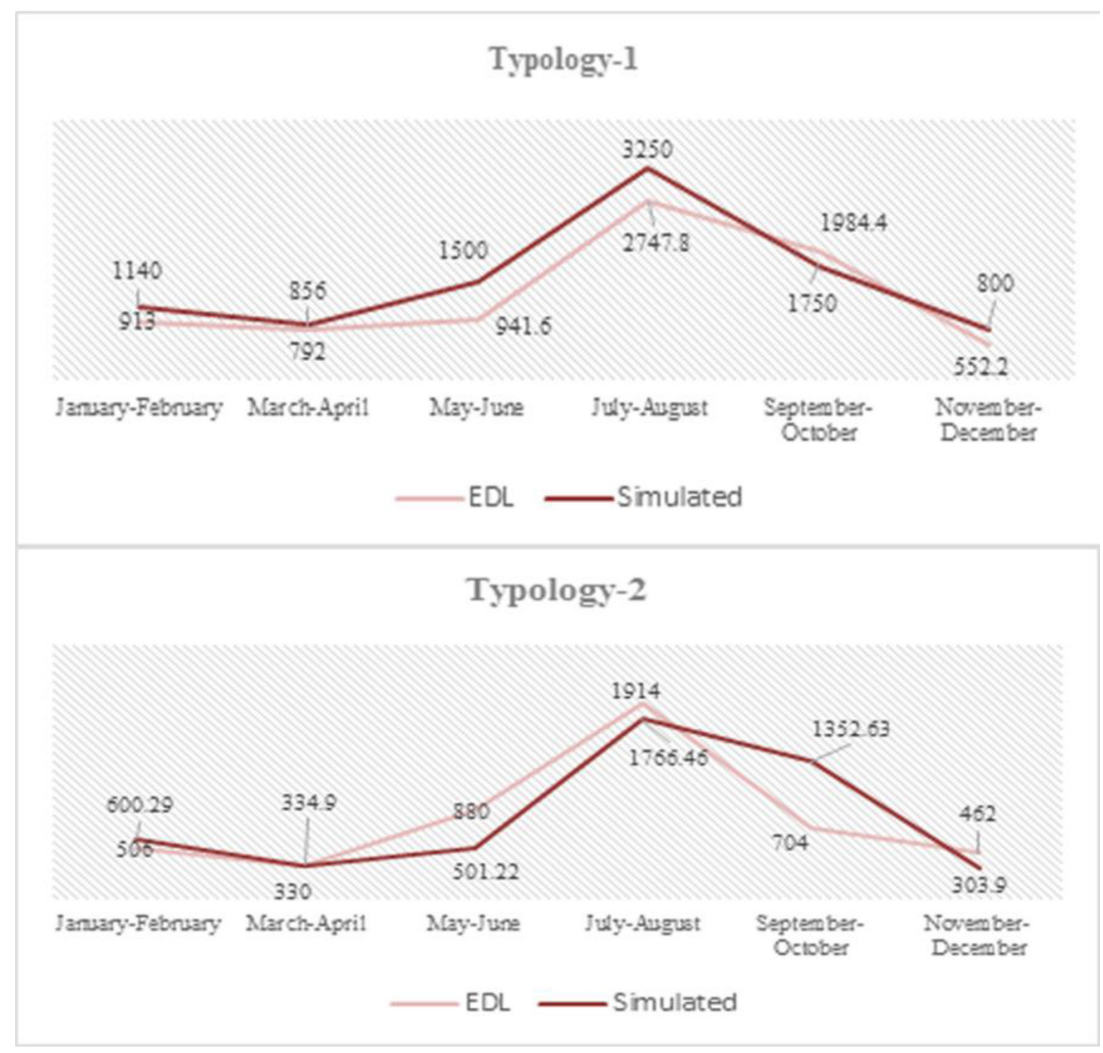

Figure 8: Comparison between simulation result and monthly electricity bill by EDL.

factors should be taken into consideration to develop a more accurate "base model". The first one will be the economic and cost factor, and the second will be the updated climate data sets due to the impact of climate change.

\section{CONCLUSION}

A method for developing and rating energy performance or a ranking procedure for residences in Lebanon has been presented in this study. The method used the questionnaire response and monitoring data to perform an energy use profile for residences and obtained model parameters for the entire residential sector in the coastal zone of Lebanon. In addition, the same approach and methodology could be applied to subsets, such as single family detached houses.

The model results showed that the penetration rates of air conditioners are the dominant in the energy usage pattern during the year. Therefore, any efficient energy measurement should focus on minimizing the usage of cooling mechanical systems by retrofitting the building envelope or use more efficient equipment. The fact that the majority of residents have never thought of any solution to reduce their electricity bills was also found in the survey result. Only $15 \%$ were aware of considering energy saving solutions. Among these, more than half have considered the installation of solar water heaters, while the others have considered energy conservation measures including energy efficient lighting (LED).

On the other hand, only seven factors which impact the energy consumption of residential buildings are considered in this paper (Building Envelope, Occupancy rates, Plug load, 
Lighting, DHW, Heating and cooling load intensities and schedules). Other factors such as the occupant's behaviour and economic issues should be added to this model as a correction function. Climate change and updated climate data should also be taken into consideration to improve the output model accuracy.

Finally, the obtained model is in line with the actual data trends to present "base model" and to help formulate Lebanese residential building energy-saving measures and standards. Variations of the benchmark building parameters may be created in a future study to meet the energy efficiency standards in order to reach Zero Energy Residential buildings in the Lebanese construction industry.

\section{ACKNOWLEDGMENTS}

We would like to thank Dr. Nabil Mohareb for his guidance in this project and Dr. Kareem Gallal for his assistance in auditing the calculation and numerical results. This research will be the base to a PhD thesis supported by the Faculty of Architectural Engineering in Beirut Arab University.

\section{REFERENCES}

[1] Jouni, A. \& Mourtada, A., Building envelope: thermal standard for buildings in lebanon. Proceeding of Sustainability Solutions Conference, MED-ENEC: Beirut, Lebanon, 2011.

[2] Tibi, G., Ghaddar, N. \& Ghali, K., Sustainable design guidelines for detached housing in the Lebanese inland region. International Journal of Sustainable Built Environment, pp. 177-193, 2012.

[3] Sharp, T.R., Energy benchmarking in commercial office buildings. Proceeding of the 1996 ACEEE Summer Study, ACEEE: Washington, DC, pp. 4321-4329, 1996.

[4] MacDonald, M. \& Livengood, S., Benchmarking residential energy use residential buildings: technologies, design, and performance analysis. Proceeding of the eceee 2013 Summer Study, ACEEE: Washington, DC, pp. 1175-1186, 2013.

[5] Aydinalp, M., Ugursal, V. \& Fung, A., Modeling of the appliance, lighting and space cooling energy consumptions in the residential sector using neural networks. Applied Energy, 71, pp. 87-110, 2002. http://dx.doi.org/10.1016/S0306-2619(01)00049-6

[6] Shehadeh, N., Energy services in Lebanon. Regional Workshop on Regulation and Certification of Energy service Providers according to article 7 of the Arab EE Guideline, Beirut, Lebanon, 2012.

[7] Climatic zoning for buildings in Lebanon, UNDP, GEF, MPWT, DGU, 2005, available at: www.test.moe.gov.lb

[8] Yaacoub, N. \& Badre, L., Population and Housing in Lebanon, Central Administration of Statics, Beirut, Lebanon, pp.15-17, 2012.

[9] Faour, G., Evaluating urban expansion using remotely-sensed data in Lebanon. Lebanese Science Journal, CNRS, 16(1), pp. 23-32, 2015.

[10] Lebanon's First National Survey Study of the Solar Water Heaters Market, Ministry of Energy and Water, UNDP, CEDRO, LCEC, March 2014, available at: www.lb.undp.org 